\title{
PENYUSUNAN ARSITEKTUR BISNIS DAN DATA PERGURUAN TINGGI SEBAGAI SUMBER DAYA AKREDITASI MENGGUNAKAN TOGAF-ADM BERORIENTASI ARTEFAK
}

\author{
Ummi Syafiqoh $\left(^{1)}\right.$ dan Rachmad Fitriyanto $\left(^{2)}\right.$ \\ ${ }^{1}$ Manajemen Informatika, STMIK PPKIA Tarakanita Rahmawati \\ ${ }^{2}$ Sistem Informasi, STMIK PPKIA Tarakanita Rahmawati \\ 1,2, Jl. Yos Sudarso No. 8 Tarakan, Kalimantan Utara, 77111 \\ E-mail: ummi@ppkia.ac.id ${ }^{1)}$,rachmad@ppkia.ac.id ${ }^{2)}$
}

\begin{abstract}
ABSTRAK
Proses Akreditasi Perguruan Tinggi merupakan proses yang membutuhkan banyak sumber daya. Bagi perguruan tinggi dengan sumber daya terbatas, penggunaan teknologi informasi dan komunikasi menjadi salah satu solusi untuk persiapan akreditasi. Permasalahan muncul ketika stakeholder dan anggota organisasi perguruan tinggi tidak memiliki informasi tentang potensi teknologi informasi yang tersedia dan dibutuhkan. Enterprise architecture merupakan blueprint untuk memahami struktur teknologi informasi dan komunikasi di organisasi. Pemanfaatan enterprise architecture memudahkan pengelola perguruan tinggi untuk memaksimalkan dan mengembangkan teknologi informasi dan komunikasi yang dimiliki. TOGAF-ADM sebagai framework enterprise architecture menawarkan fleksibilitas dan sifat generik penggunaan artefak enterprise architecture. Sifat fleksibel dan generik ini menjadi masalah dikarenakan cakupannya yang sangat luas menyebabkan banyaknya opsi artefak yang disediakan. Penelitian-penelitian yang disebutkan sebelumnya, belum mencantumkan alasan pemilihan artefak yang digunakan.. Penelitian ini bertujuan untuk menyusun arsitektur bisnis dan data dengan framework TOGAF-ADM berorientasi artefak. Penelitian dilakukan dalam 4 tahap. Tahap pertama, implementasi preliminary phase, diikuti tahap kedua fase architecture vision. Tahap ketiga fase Business Architecture dan tahap keempat fase information system architecture. Hasil yang diperoleh tersusun 8 artefak. Artefak katalog prinsip tersusun dari 2 prinsip bisnis, 1 prinsip data, 2 prinsip aplikasi dan 1 prinsip teknologi. Artefak functional decomposition diagram baseline dan target menunjukkan diperlukannya empat proses bisnis tambahan meliputi manajemen data tracer study, evaluasi penelitian dosen, evaluasi pengabdian dosen, monitoring penelitian dosen, monitoring pengabdian dosen dan manajemen data dosen dan mahasiswa. Pada artefak organizational decomposition diagram dan role catalogue terdapat tugas dan peran setiap stakeholder terkait proses akreditasi. Artefak data entity/business function matrix dan data to role access matrix berisikan entitas data yang digunakan dalam proses akreditasi serta tugas dari setiap stakeholder terkait dengan pengelolaan data.
\end{abstract}

Kata Kunci: Enterprise Architecture, TOGAF-ADM, Akreditasi, Artefak, Business Architecture, Data Architecture

\section{PENDAHULUAN}

Kualitas sebuah perguruan tinggi (PT) diukur dari tingkat akreditasi yang dimilikinya. Pengukuran tingkat akreditasi mengacu kepada Tridharma PT, yaitu kewajiban perguruan tinggi untuk menyelenggarakan pendidikan, penelitian dan pengabdian kepada masyarakat (Undang-Undang No.12 Tahun 2012 Tentang Pendidikan Tinggi, 2012). Ketiga kegiatan tersebut dilaksanakan oleh berbagai unit internal organisasi PT dalam bentuk proses bisnis. Lembaga Penjaminan Mutu Internal (LPMI) merupakan unit internal PT yang bertugas untuk mengawasi pelaksanaan standar penjaminan mutu internal (SPMI). Pengawasan yang dilakukan LPMI terhadap SPMI membutuhkan interaksi antara unit LPMI dengan unit-unit lain di internal PT. Interaksi dibutuhkan untuk mengumpulkan data dan informasi terkait pelaksanaan SPMI. Proses pengawasan membuat LMPI membutuhkan sumber daya manusia (SDM) yang cukup. Permasalahan pelaksanaan tugas LPMI muncul Ketika SDM yang dimiliki LPMI terbatas yang ditemui pada PT yang baru berdiri dan berkembang.

Penerapan teknologi informasi dan komunikasi (TIK) menjadi solusi untuk memudahkan proses pengawasan oleh LPMI, namun penerapan TIK sering dilakukan secara insidental tanpa adanya perencanaan yang baik sehingga menyebabkan fungsionalitas TIK yang dimiliki tidak dapat dimaksimalkan. Hal ini disebabkan organisasi tidak memiliki pengetahuan dan wawasan yang cukup tentang fungsi bisnis organisasi, proses bisnis, ketersediaan aset (hardware-software) dan kebutuhan TIK (Niemi \& Pekkola, 2020; Yudatama et al., 2018). Kondisi tersebut dapat dihindari dan diantisipasi dengan perencanaan yang tepat.

Arsitektur enterprise atau enterprise architecture (EA) merupakan cetak biru teknologi informasi organisasi (Rouhani et al., 2015; Suryana, 2017). EA merupakan dokumentasi arsitektur teknologi informasi 
yang dikembangkan dari proses bisnis organisasi. EA berperan penting bagi organisasi untuk menyelaraskan agar penerapan teknologi informasi dapat mendukung proses bisnis yang pada akhirnya mencapai visi, misi dan tujuan organisasi (Foorthuis et al., 2016; Setiawan, 2015). Penggunaan EA juga memberikan manfaat bagi organisasi untuk melakukan standarisasi proses bisnis dan mengintegrasikan sistem-sistem yang berada di masing-masing unit internal untuk mencapai tujuan utama organisasi (Saleem \& Fakieh, 2020). Manfaat lain yang diperoleh bagi organisasi adalah kemudahan untuk memaksimalkan dan mengembangkan teknologi informasi dan komunikasi yang dimiliki

Metode penyusunan EA dilakukan dengan menerapkan framework EA. Beberapa framework EA yang umum digunakan adalah DoDAF, NAF, MODAF, UAF, FEAF, Zachman dan TOGAF (Eichmann et al., 2019; Kurniawan, 2011). The Open Group Architectural Framework (TOGAF) adalah framework yang dikembangkan untuk menyusun EA berbasis prinsipprinsip organisasi yang terdiri dari 3 prinsip yaitu, prinsip pendukung keputusan, prinsip penyediaan pedoman sumber daya teknologi informasi dan prinsip pengembangan dan implementasi teknologi informasi . TOGAF merupakan kerangka EA yang dikembangkan oleh The Open Group Architecture Framework pada tahun 1995, yang awalnya hanya digunakan oleh Departemen Pertahanan Amerika Serikat (Tao et al., 2017). Hak penggunaan EA dari TOGAF yang bersifat open source membuat framework ini banyak digunakan oleh berbagai pihak. Fleksibilitas pengimplementasian framework ini menjadi salah alasan lain yang membuat berbagai organisasi menggunakan TOGAF.

Metode perancangan EA yang dimiliki TOGAF disebut dengan Architecture Development Method atau sering disingkat dengan istilah TOGAF ADM (Proenca \& Borbinha, 2017; Setiawan, 2015). Penelitianpenelitian yang membahas penerapan TOGAF-ADM telah banyak dilakukan, dan menyimpulkan bahwa sifat fleksibel dan generik menjadi alasan penggunaan framework tersebut (Arif Abdul Hakim et al., 2019; Gefan, 2018; Soraya \& Sari, 2019; Thea Nisaa'Andi et al., 2019).

Sifat fleksibel dan generik yang dimiliki framework TOGAF-ADM dapat menjadi masalah dikarenakan cakupannya yang sangat luas. Perencana EA yang menjadi bagian di PT yang belum memiliki pengalaman penyusunan EA mengalami permasalahan dikarenakan banyaknya opsi artefak yang disediakan. Penelitianpenelitian yang disebutkan sebelumnya, belum mencantumkan alasan pemilihan artefak yang digunakan. Permasalahan serupa ditemui di institusi tempat penelitian ini dilakukan.

Solusi dari permasalahan di atas adalah dengan mendefinisikan karakteristik artefak sesuai dengan kebutuhan di organisasi. Setiap artefak memiliki definisi dan tujuan penyusunan serta karakteristik yang berbedabeda. Pemahaman tentang setiap artefak dapat digunakan sebagai salah satu cara bagi perencana EA di PT untuk menerapkan TOGAF-ADM. Pemahaman artefak merupakan bagian dari tahap requirements management dalam framework TOGAF-ADM yang jarang di eksplorasi dari penelitian-penelitian sebelumnya. Pendefinisian artefak dan penyusunan kebutuhan data pada tahap requirements management menjadi dasar yang jarang dibahas menjadi dasar dilaksanakannya penelitian ini untuk menyusun arsitektur bisnis dan data di unit LPMI-PT berorientasi artefak TOGAF-ADM.

\section{RUANG LINGKUP}

Ruang lingkup pada penelitian ini adalah menyusun arsitektur bisnis dan arsitektur data menggunakan TOGAF-ADM. Permasalahan dalam penelitian ini adalah bagaimana cara menyusun arsitektur bisnis dan data berorientasi artefak pada TOGAF-ADM untuk proses pemenuhan syarat akreditasi perguruan tinggi. Penelitian ini dilakukan di lingkup LPMI yang berkaitan dengan proses pemenuhan persyaratan akreditasi perguruan tinggi. Luaran dari penelitian ini adalah artefak arsitektur bisnis dan data.

\section{BAHAN DAN METODE}

Pada bagian ini menjelaskan bahan-bahan dan metode penelitian yang digunakan dalam penelitian ini.

\subsection{TOGAF-ADM}

Framework TOGAF-ADM tersusun dari 8 fase (Desfray \& Raymond, 2014; Nambela et al., 2020) seperti diilustrasikan pada Gambar 1.

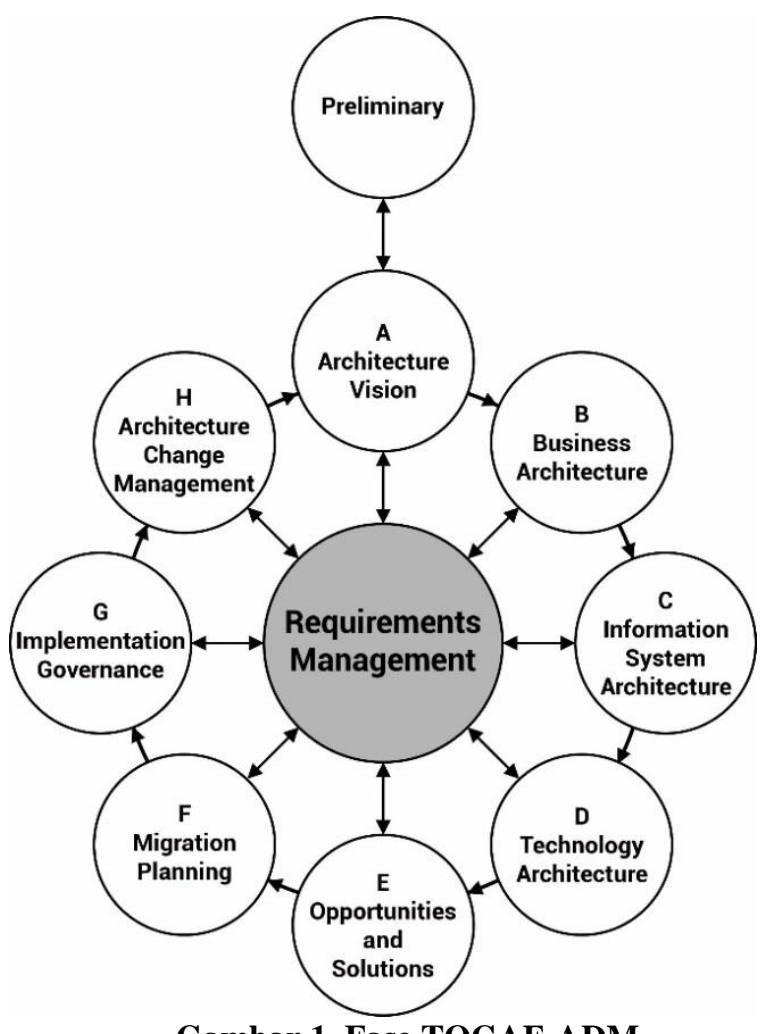

Gambar 1. Fase TOGAF-ADM 
Kedelapan fase di Gambar 1, digunakan untuk memenuhi 3 prinsip utama EA yang terdiri dari prinsip Enterprise, prinsip teknologi informasi dan prinsip arsitektur. Prinsip enterprises menjadi acuan agar arsitektur yang dikembangkan harus mampu mendukung aktivitas yang berlangsung di setiap unit di dalam organisasi. Prinsip Teknologi Informasi menjadi acuan agar arsitektur yang dikembangkan mampu mendorong digunakannya berbagai bentuk teknologi informasi yang sesuai dengan kebutuhan di setiap unit di dalam organisasi. Prinsip Arsitektur menjadi acuan agar arsitektur teknologi informasi dikembangkan berdasarkan kebutuhan proses bisnis yang berlangsung di setiap unit di dalam organisasi.

Kedelapan fase diawali dengan tahap preliminary yang berisikan aktivitas identifikasi kebutuhan stakeholder EA. Hasil tahap ini diikuti fase A sampai dengan fase G. Setiap fase akan melalui tahap requirements management yang bersifat dua arah. Hal ini membuat sebuah fase yang telah dijalankan dapat diubah dengan diawali proses requirement management dari fase mana pun. Setiap tahapan TOGAF-ADM, memiliki standar output yang harus dihasilkan yang disebut dengan artefak (Ansyori et al., 2018; Harrison, 2010). Artefak yang dihasilkan di setiap tahap dan fase TOGAF-ADM dirumuskan seperti pada Tabel 1.

Tabel 1. Artefak Pada TOGAF-ADM

\begin{tabular}{|c|c|}
\hline Fase & Artefak \\
\hline $\begin{array}{l}\text { Fase } \\
\text { preliminary }\end{array}$ & Principles Catalogue \\
\hline $\begin{array}{l}\text { Fase A: } \\
\text { Architecture } \\
\text { vision }\end{array}$ & $\begin{array}{l}\text { 1. Matrix Stakeholder map } \\
\text { 2. Diagram value chain } \\
\text { 3. Diagram solution concept }\end{array}$ \\
\hline $\begin{array}{l}\text { Fase B: } \\
\text { Business } \\
\text { Architecture }\end{array}$ & $\begin{array}{l}\text { 1. Role catalogue } \\
\text { 2. Actor Role Matrix } \\
\text { 3. Organization/Actor Catalogue } \\
\text { 4. Existing business process diagram } \\
\text { 5. Future business process diagram }\end{array}$ \\
\hline $\begin{array}{l}\text { Fase C: } \\
\text { Information } \\
\text { System } \\
\text { Architecture }\end{array}$ & $\begin{array}{l}\text { 1. Data entity catalogue } \\
\text { 2. Data entity matrix } \\
\text { 3. Logical data diagram } \\
\text { 4. Physical data diagram } \\
\text { 5. Matrix akses data }\end{array}$ \\
\hline $\begin{array}{l}\text { Fase D: } \\
\text { Technology } \\
\text { Architecture }\end{array}$ & $\begin{array}{l}\text { 1. Technology standards catalogue } \\
\text { 2. Platform Decomposition Diagram } \\
\text { 3. Communication Diagram }\end{array}$ \\
\hline $\begin{array}{l}\text { Fase E: } \\
\text { Opportunities } \\
\text { \& Solutions }\end{array}$ & $\begin{array}{l}\text { 1. Project Context Diagram } \\
\text { 2. Benefits Diagram }\end{array}$ \\
\hline
\end{tabular}

Artefak-artefak yang tercantum di Tabel 1 dapat dikelompokkan menjadi 3 jenis artefak, katalog, matriks dan diagram. TOGAF tidak mengharuskan penyusun EA untuk menggunakan semua artefak, namun menyesuaikan sesuai kebutuhan dan kebiasaan penggunaan data dan informasi di organisasi, selama informasi yang tersimpan di artefak dapat dipahami oleh pengembang TOGAF-ADM dan stakeholder.

\subsection{Metode Penelitian}

Penelitian dilakukan dalam 4 tahap sesuai kerangka kerja TOGAF-ADM. Tahap pertama adalah pelaksanaan fase preliminary. Tahap kedua penyusunan visi arsitektur. Tahap ketiga penyusunan arsitektur bisnis dan tahap keempat penyusunan arsitektur sistem informasi. Gambar 2 menunjukkan keempat tahapan tersebut.

\begin{tabular}{|c|c|}
\hline \multicolumn{2}{|c|}{ PRELIMINARY PHASE } \\
\hline $\begin{array}{l}\text { Requirements } \\
\text { Management }\end{array}$ & $\begin{array}{l}\text { 1. Pendefinisian Artifak } \\
\text { 2. Identifikasi Kebutuhan Data Artifak } \\
\text { 3. Pengumpulan Data }\end{array}$ \\
\hline Peny & $\begin{array}{l}\text { 1. Katalog Prinsip Bisnis } \\
\text { 2. Katalog Prinsip Data } \\
\text { 3. Katalog Prinsip Aplikasi } \\
\text { 4. katalog Prinsip Teknologi }\end{array}$ \\
\hline & ARCHITECTURE VISION \\
\hline $\begin{array}{l}\text { Requirements } \\
\text { Management }\end{array}$ & $\begin{array}{l}\text { 1. Pendefinisian Artifak } \\
\text { 2. Identifikasi Kebutuhan Data Artifak } \\
\text { 3. Pengumpulan Data }\end{array}$ \\
\hline $\begin{array}{r}\text { Penyusur } \\
\text { Artifak }\end{array}$ & $\begin{array}{l}\text { 1. Stakeholder Map Diagram } \\
\text { 2. Chain Value Diagram } \\
\text { 3. Concept Solution Diagram }\end{array}$ \\
\hline & BUSINESS ARCHITECTURE \\
\hline & $\begin{array}{l}\text { 1. Pendefinisian Artifak } \\
\text { 2. Identifikasi Kebutuhan Data Artifak } \\
\text { 3. Pengumpulan Data }\end{array}$ \\
\hline tifak & $\begin{array}{l}\text { 1. Functional decomposition baseline } \\
\text { 2. Functional decomposition target } \\
\text { 3. Organization decomposition diagram } \\
\text { 4. Role Catalog }\end{array}$ \\
\hline & $\begin{array}{c}\text { INFORMATION SYSTEM } \\
\text { ARCHITECTURE }\end{array}$ \\
\hline $\begin{array}{l}\text { Requirements } \\
\text { Management }\end{array}$ & $\begin{array}{l}\text { 1. Pendefinisian Artifak } \\
\text { 2. Identifikasi Kebutuhan Data Artifak } \\
\text { 3. Pengumpulan Data }\end{array}$ \\
\hline $\begin{array}{l}\text { Penyusunan } \\
\text { Artifak }\end{array}$ & $\begin{array}{l}\text { 1. Data entity/business function matrix } \\
\text { 2. Data to role access matrix }\end{array}$ \\
\hline
\end{tabular}

Gambar 2. Tahapan Penelitian

Keempat tahap yang ditunjukkan pada Gambar 2, memiliki kesamaan pada sub proses requirements management, yang terdiri dari aktivitas pendefinisian artefak, identifikasi kebutuhan data untuk artefak dan pengumpulan data. Pendefinisian artefak bertujuan untuk mengetahui karakteristik dan fungsi dari artefak. Karakteristik artefak dirumuskan dari hasil studi literatur terkait penelitian-penelitian tentang EA TOGAF-ADM, dan sumber-sumber lain.

Identifikasi kebutuhan artefak berisikan aktivitas perumusan kebutuhan data dan informasi untuk penyusunan artefak. Proses pengumpulan data dilakukan dengan menghubungi unit-unit internal organisasi (PT) 
yang memiliki data dan informasi yang dibutuhkan untuk penyusunan artefak

\section{PEMBAHASAN}

Bagian ini merumuskan hasil penerapan metode penelitian. Bagian ini tersusun dari 4 sub bab yang merepresentasikan empat fase TOGAF-ADM, preliminary phase, architecture vision, business architecture dan information system and data architecture.

\subsection{Preliminary Phase}

Pelaksanaan fase preliminary bertujuan untuk menentukan sudut pandang dan artefak-artefak yang akan digunakan di dalam EA. Pada tahap ini harus diidentifikasi stakeholder yang berperan dalam penyusunan EA. Daftar stakeholder yang diperoleh digunakan untuk menyusun sudut pandang stakeholder terhadap EA (Desfray \& Raymond, 2014; Murti et al., 2017).

Fase preliminary terdiri dari 3 aktivitas, identifikasi proses bisnis utama yang berkaitan dengan proses akreditasi PT, identifikasi permasalahan yang akan diselesaikan serta penyusunan prinsip bisnis, prinsip data, prinsip aplikasi dan prinsip teknologi. Proses bisnis utama dan permasalahan yang berhasil diidentifikasi adalah ketersediaan data dan informasi tentang penerimaan mahasiswa baru, penyelenggaraan perkuliahan, penelitian dosen dan informasi tentang pengabdian masyarakat. Data dan informasi dari keempat proses bisnis tersebut masih tersimpan di bagian masingmasing dan pengumpulannya masih dilakukan dengan komunikasi interpersonal.

Berdasarkan permasalahan di keempat proses bisnis tersebut, disusun artefak berupa katalog prinsip yang memiliki karakteristik sebagai berikut (Desfray \& Raymond, 2014; Wijaya, 2017):

1. Katalog prinsip terdiri dari 4 komponen

2. Komponen nama prinsip dibuat se-unik mungkin yang mampu merepresentasikan tujuan yang ingin dicapai

3. Komponen pernyataan berisikan deskripsi ringkas yang tentang permasalahan yang akan diselesaikan

4. Komponen dasar pemikiran (rationale) berisikan hal yang mendasari dibutuhkannya arsitektur. Dasar pemikiran juga berisikan manfaat yang dapat diperoleh dari implementasi arsitektur terhadap proses bisnis. Dasar pemikiran juga harus dilengkapi dengan uraian hubungan antara prinsip satu dengan prinsip lainnya.

5. Komponen implikasi berisikan persyaratan yang harus dipenuhi untuk menjalankan prinsip arsitektur. Persyaratan berkaitan dengan proses bisnis dan teknologi informasi

Katalog prinsip bisnis yang berhasil disusun terdiri dari 2 prinsip, dengan kode PB01 dan PB02 ditunjukkan pada Tabel 2 dan 3
Tabel 2. Katalog Prinsip Bisnis PB01

\begin{tabular}{|c|c|}
\hline Nama Prinsip & Proses bisnis Terencana \\
\hline Kode & PB01 \\
\hline Pernyataan & $\begin{array}{l}\text { Proses bisnis harus terprogram/terencana } \\
\text { agar efisien }\end{array}$ \\
\hline Dasar Pemikiran & $\begin{array}{l}\text { 1. Proses bisnis yang terencana } \\
\text { memudahkan pelaku proses bisnis } \\
\text { untuk bekerja sesuai kebutuhan unit } \\
\text { untuk mencapai target masing-masing } \\
\text { unit } \\
\text { 2. Perencanaan proses bisnis harus sesuai } \\
\text { dengan visi, misi, tujuan organisasi }\end{array}$ \\
\hline Implikasi & $\begin{array}{l}\text { 1. Organisasi harus memiliki deskripsi } \\
\text { tugas dan tanggung jawab yang jelas } \\
\text { untuk setiap unit. } \\
\text { 2. Unit harus memiliki program kerja } \\
\text { yang deskriptif, jelas dan mudah diukur } \\
\text { 3. Unit harus memiliki alur proses bisnis } \\
\text { yang terencana dengan baik, jelas } \\
\text { pembagian tugas dan terdokumentasi } \\
\text { dengan baik. } \\
\text { 4. Pemodelan proses bisnis menggunakan } \\
\text { satu jenis perangkat bantu / tool yang } \\
\text { mudah diperoleh dan dipahami oleh } \\
\text { setiap unit internal organisasi }\end{array}$ \\
\hline
\end{tabular}

Tabel 3. Katalog Prinsip Bisnis PB02

\begin{tabular}{|c|c|}
\hline Nama Prinsip & Non Redundansi \\
\hline Kode & PB02 \\
\hline Pernyataan & $\begin{array}{l}\text { Proses bisnis yang sama dan berulang di } \\
\text { dua unit atau lebih merupakan pemborosan } \\
\text { waktu dan tenaga yang menghambat } \\
\text { percepatan pencapaian target kerja } \\
\text { masing-masing unit }\end{array}$ \\
\hline Dasar Pemikiran & $\begin{array}{l}\text { Proses bisnis yang tidak redundansi atau } \\
\text { tidak tumpang tindih akan mempercepat } \\
\text { terselesaikan nya program kerja setiap unit }\end{array}$ \\
\hline Implikasi & $\begin{array}{l}\text { 1. Unit internal organisasi harus memiliki } \\
\text { komunikasi yang baik dengan unit lain } \\
\text { 2. Setiap unit harus saling bekerja sama } \\
\text { untuk menyusun model proses bisnis } \\
\text { 3. Setiap proses bisnis yang dilakukan di } \\
\text { satu unit harus bersifat unik dan } \\
\text { berbeda dengan unit lain }\end{array}$ \\
\hline
\end{tabular}

Katalog prinsip data terdiri dari satu prinsip dengan kode PD01, ditunjukkan pada Tabel 4. 
Tabel 4. Katalog Prinsip Data

\begin{tabular}{|c|c|}
\hline Nama Prinsip & Kepemilikan Data \\
\hline Kode & PD01 \\
\hline Pernyataan & $\begin{array}{l}\text { Ketidakjelasan status kepemilikan data } \\
\text { membuat proses bisnis di unit dan antar } \\
\text { unit menjadi tidak efisien. Aktor / } \\
\text { stakeholder proses bisnis dimungkinkan } \\
\text { melakukan proses yang redundansi }\end{array}$ \\
\hline Dasar Pemikiran & $\begin{array}{l}\text { Kejelasan status kepemilikan data akan } \\
\text { meringkas proses bisnis yang dapat } \\
\text { mempercepat tercapainya target program } \\
\text { kerja unit }\end{array}$ \\
\hline Implikasi & $\begin{array}{l}\text { 1. Aturan kepemilikan dan hak akses data } \\
\text { harus disusun dalam bentuk kebijakan } \\
\text { yang diterapkan di setiap level dan } \\
\text { setiap unit di dalam organisasi } \\
\text { 2. Pengaturan status kepemilikan data } \\
\text { harus sesuai dengan proses bisnis yang } \\
\text { berlaku di organisasi }\end{array}$ \\
\hline
\end{tabular}

Katalog prinsip aplikasi yang berhasil disusun terdiri dari 3 prinsip dengan kode PA01, PA02 dan PA03. Tabel 5 menunjukkan katalog prinsip untuk kode PA01.

Tabel 5. Katalog Prinsip Integrasi Aplikasi

\begin{tabular}{|l|l|}
\hline Nama Prinsip & Integrasi Aplikasi \\
\hline Kode & PA01 \\
\hline Pernyataan & $\begin{array}{l}\text { Unit dan karyawan membutuhkan } \\
\text { aplikasi/sistem informasi agar beban kerja } \\
\text { dapat di manajemen dengan baik. Setiap } \\
\text { aplikasi memiliki peruntukan yang } \\
\text { berbeda yang disesuaikan dengan proses } \\
\text { bisnis yang dijalankan. Aplikasi juga } \\
\text { difungsikan sebagai media komunikasi } \\
\text { antar unit }\end{array}$ \\
\hline Dasar Pemikiran & \begin{tabular}{l} 
1. $\begin{array}{l}\text { Penggunaan aplikasi/sistem informasi } \\
\text { akan memudahkan pelaku proses } \\
\text { bisnis untuk manajemen tugasnya } \\
\text { sehingga dapat mempercepat } \\
\text { pencapaian target program kerja } \\
\text { Integrasi aplikasi antar unit akan } \\
\text { meningkatkan efisiensi waktu kerja }\end{array}$ \\
\hline Implikasi
\end{tabular} 1. $\begin{array}{l}\text { Mengintegrasikan aplikasi dilakukan } \\
\text { berdasarkan alur proses bisnis } \\
\text { organisasi } \\
\text { Mengintegrasikan aplikasi tidak boleh } \\
\text { menghambat pelaksanaan prinsip- } \\
\text { prinsip bisnis organisasi. }\end{array}$ \\
\hline
\end{tabular}

Prinsip integrasi aplikasi ditetapkan oleh stakeholder perguruan tinggi agar aplikasi yang dirancang dan dibangun dapat mengintegrasikan satu dengan lainnya untuk meningkatkan efisiensi kerja di setiap unit yang menggunakan. Aplikasi juga harus dapat digunakan dengan mudah seperti ditunjukkan pada prinsip aplikasi PA02 seperti pada Tabel 6 .

Tabel 6. Katalog Prinsip Kemudahan Operasional

\begin{tabular}{|l|l|}
\hline Nama Prinsip & Kemudahan Operasional \\
\hline Kode & PA02 \\
\hline Pernyataan & $\begin{array}{l}\text { Aplikasi harus mudah digunakan untuk } \\
\text { setiap unit organisasi }\end{array}$ \\
\hline
\end{tabular}

\begin{tabular}{|c|c|}
\hline $\begin{array}{l}\text { Dasar } \\
\text { Pemikiran }\end{array}$ & $\begin{array}{l}\text { Aplikasi yang dibangun sesuai kebutuhan } \\
\text { user di setiap unit, mudah digunakan dan } \\
\text { dapat memudahkan user untuk } \\
\text { meningkatkan performa untuk } \\
\text { pelaksanaan proses bisnis }\end{array}$ \\
\hline Implikasi & $\begin{array}{l}\text { 1. Setiap unit harus memiliki deskripsi } \\
\text { karakteristik user terkait dengan } \\
\text { penggunaan aplikasi. } \\
\text { 2. Aplikasi dapat dipelajari dengan } \\
\text { cepat sesuai dengan level kebutuhan } \\
\text { user } \\
\text { 3. Aplikasi harus dapat memproses } \\
\text { setiap bentuk data yang dihasilkan } \\
\text { dan dibutuhkan di masing-masing } \\
\text { unit }\end{array}$ \\
\hline
\end{tabular}

Prinsip terakhir dari fase preliminary adalah prinsip teknologi dirumuskan dalam Tabel 7.

Tabel 7. Prinsip Teknologi

\begin{tabular}{|l|l|}
\hline Nama Prinsip & Upgradable dan Updatable \\
\hline Kode & PT01 \\
\hline Dernyataan & $\begin{array}{l}\text { Teknologi yang dipilih harus mampu } \\
\text { mendukung pelaksanaan proses bisnis } \\
\text { memberektif. Teknologi tidak boleh }\end{array}$ \\
\hline masar Pemikiran permasalahan baru
\end{tabular}

Bagian pernyataan di setiap katalog prinsip dirumuskan berdasarkan permasalahan yang ditemui pada proses akreditasi di perguruan tinggi. Bagian implikasi dirumuskan berdasarkan tindakan yang harus dilakukan untuk mencari solusi dari permasalahan di bagian pernyataan 


\subsection{Phase A Architecture Vision}

Tahap Penyusunan Visi Arsitektur bertujuan untuk menyusun tiga artefak, matrix Stakeholder map, diagram value chain dan diagram solution concept. Ketiga artefak tersebut membutuhkan data berupa struktur organisasi perguruan tinggi, deskripsi tugas dan tanggung jawab unit organisasi, visi-misi organisasi dan konsep rancangan sistem informasi yang akan dibangun. Gambar 3 menunjukkan diagram chain value dari fase $\mathrm{A}$.

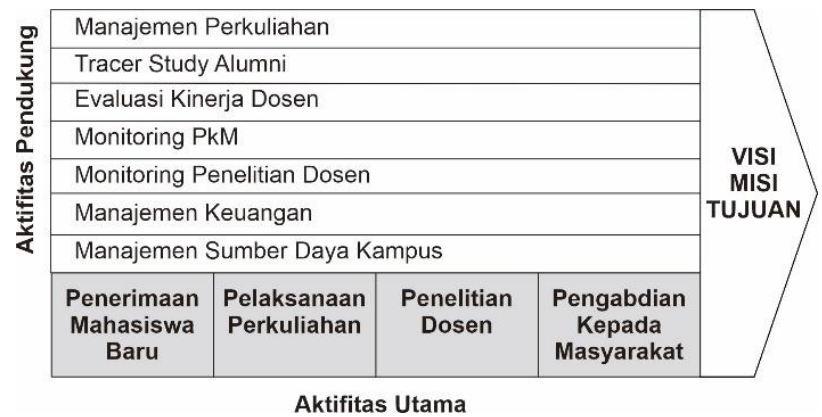

Gambar 3. Diagram Chain Value

Penyusunan diagram chain value dilakukan berdasarkan proses bisnis utama yang diselenggarakan di tingkat perguruan tinggi terdiri. Setiap aktivitas utama dan pendukung memiliki stakeholder utama yang memiliki peran dan kepentingan terkait dengan EA dan akreditasi PT. Rumusan peran dan tingkat kepentingan tersebut menjadi isi artefak matriks stakeholder map seperti ditunjukkan pada Tabel 8. Artefak matriks stakeholder pada Tabel 8 bersama dengan deskripsi tujuan penyusunan EA dan informasi aplikasi yang sedang digunakan, digunakan untuk menyusun conceptsolution diagram seperti ditunjukkan pada Gambar 4.

Tabel 8. Matriks Stakeholder Map

\begin{tabular}{|l|l|c|c|}
\hline Nama & \multicolumn{1}{|c|}{ Peran } & $\begin{array}{c}\text { Tingkat } \\
\text { Pengambilan } \\
\text { Keputusan }\end{array}$ & $\begin{array}{c}\text { Tingkat } \\
\text { Kepentingan }\end{array}$ \\
\hline $\begin{array}{l}\text { Pimpinan } \\
\text { PT }\end{array}$ & $\begin{array}{l}\text { Pengambil } \\
\text { keputusan } \\
\text { berorientasi } \\
\text { visi misi PT }\end{array}$ & Tinggi & Tinggi \\
\hline $\begin{array}{l}\text { Ketua } \\
\text { Senat }\end{array}$ & $\begin{array}{l}\text { Pengawas } \\
\text { kualitas } \\
\text { manajemen PT }\end{array}$ & Tinggi & Tinggi \\
\hline Ka.Prodi & $\begin{array}{l}\text { Manajemen } \\
\text { perkuliahan }\end{array}$ & Tinggi & Sedang \\
\hline Ka.LPSI & $\begin{array}{l}\text { Pengembangan } \\
\text { sistem } \\
\text { informasi }\end{array}$ & Sedang & Sedang \\
\hline Ka.LPMI & $\begin{array}{l}\text { Pengawas } \\
\text { mutu } \\
\text { pengelolaan PT }\end{array}$ & Tinggi & Tinggi \\
\hline Ka.LPPM & $\begin{array}{l}\text { Manajemen } \\
\text { penelitian dan } \\
\text { pengabdian } \\
\text { dosen }\end{array}$ & Sedang & Sedang \\
\hline
\end{tabular}

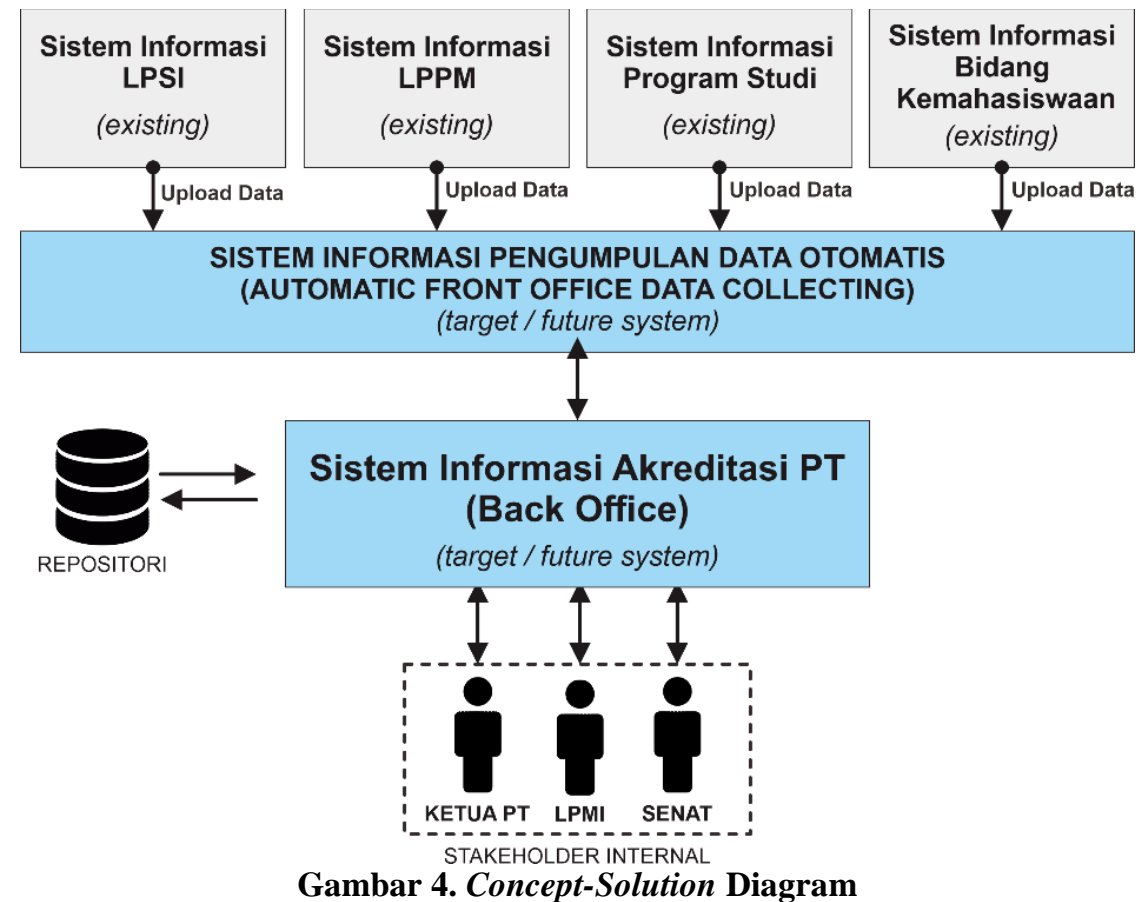

Diagram konsep solusi pada Gambar 4 tersusun dari 2 jenis sistem, sistem internal dan eksternal. Sistem internal adalah sistem yang akan digunakan oleh stakeholder utama, yaitu pihak yang melaksanakan 
persiapan akreditasi, yang terdiri dari 3 stakeholder utama. Sistem internal tersusun dari 2 jenis sistem informasi, front office dan back office, sesuai dengan peruntukan penggunanya.

Sistem front office digunakan sebagai sistem pengumpul data otomatis dari 3 sistem eksternal di LPSI, LPPM dan Program Studi. Ketiga sistem eksternal merupakan sistem existing yang telah tersedia dan sudah digunakan. Sistem Back office digunakan khusus oleh stakeholder utama. Sistem front office dan back office merupakan sistem target yang akan dibangun berdasarkan EA yang disusun.

\subsection{Phase B Business Architecture}

Fase Business Architecture bertujuan untuk mendeskripsikan proses bisnis yang akan dibenahi melalui deskripsi proses bisnis yang sedang berjalan (baseline) dan proses bisnis yang akan dibangun (target), serta stakeholder yang terlibat di kedua proses bisnis tersebut. Kedua macam proses bisnis tersebut menjadi dasar penyusunan artefak business function decomposition diagram seperti ditunjukkan pada Gambar 5 dan 6.

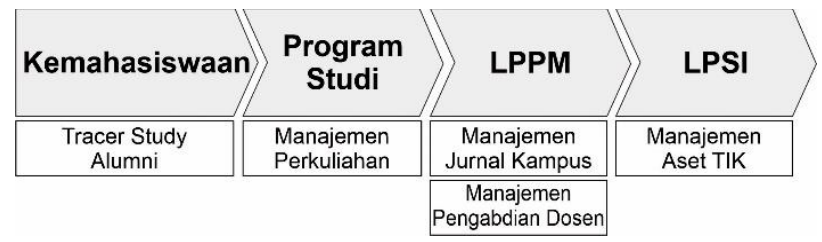

\section{Gambar 5. Baseline Business Decomposition Diagram}

Baseline business decomposition diagram menggambarkan aktivitas utama di setiap bagian organisasi PT yang sedang berjalan. Artefak ini disusun berdasarkan artefak diagram chain value dari fase Architecture Vision. Baseline business decomposition diagram dikembangkan menjadi Target business decomposition diagram dengan menambahkan proses bisnis yang dibutuhkan untuk mencapai visi, misi PT. Gambar 6 menunjukkan artefak target business decomposition diagram.

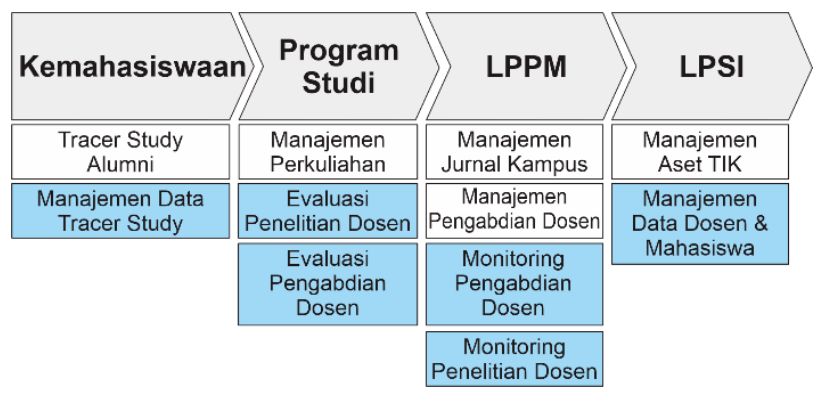

\section{Gambar 6. Target Business Decomposition Diagram}

Target business decomposition diagram merupakan pengembangan dari baseline, dengan menambahkan proses bisnis yang harus dilakukan. Pada penelitian ini, proses bisnis yang ditambahkan berkaitan dengan pengelolaan data yang dibutuhkan dalam proses akreditasi PT, ditunjukkan pada blok berwarna di Gambar 5, meliputi manajemen data tracer study, evaluasi penelitian dosen, evaluasi pengabdian dosen, monitoring penelitian dosen, monitoring pengabdian dosen dan manajemen data dosen dan mahasiswa.

Setiap proses bisnis di lingkup masing-masing bagian PT, memiliki aktor yang menjalankan satu atau lebih peran (role) dan dapat di deskripsi dalam bentuk artefak organization decomposition diagram seperti ditunjukkan pada Gambar 7.

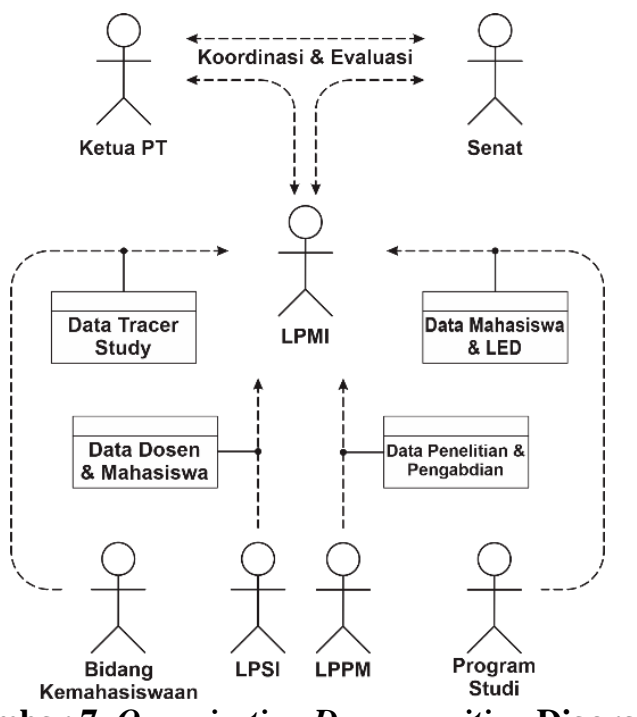

Gambar 7. Organization Decomposition Diagram

Diagram pada Gambar 7 menunjukkan komposisi stakeholder yang terlibat dalam proses akreditasi PT dan aliran informasi yang muncul pada proses tersebut. Pada artefak organization decomposition diagram, muncul stakeholder LPMI bersama Pimpinan PT (ketua). Objek dari setiap aliran menunjukkan terjadi proses bisnis diantara aktor-aktor. Rumusan roses bisnis tersebut dirumuskan dalam artefak role catalogue untuk setiap stakeholder, seperti ditunjukkan pada Tabel $9,10,11,12$ dan 13.

Tabel 9. Role Catalogue Ka.LPPM

\begin{tabular}{|l|l|}
\hline Aktor & Ka.LPPM \\
\hline Role & $\begin{array}{l}\text { Pengelolaan perkembangan penelitian } \\
\text { dosen dan pengabdian dosen }\end{array}$ \\
\hline $\begin{array}{l}\text { Tanggung } \\
\text { Jawab }\end{array}$ & $\begin{array}{l}\text { Penyediaan data penelitian dosen dan } \\
\text { pengabdian dosen }\end{array}$ \\
\hline $\begin{array}{l}\text { Tujuan pada } \\
\text { EA }\end{array}$ & $\begin{array}{l}\text { Tersedianya informasi peluang dan jumlah } \\
\text { publikasi penelitian, pengabdian dosen } \\
\text { yang up-to-date }\end{array}$ \\
\hline
\end{tabular}


Tabel 10. Role Catalogue Ka.LPSI

\begin{tabular}{|l|l|}
\hline Aktor & Ka.LPSI \\
\hline Role & $\begin{array}{l}\text { Pengelolaan aset teknologi informasi dan } \\
\text { komunikasi dan Sinkronisasi data PDPT }\end{array}$ \\
\hline $\begin{array}{l}\text { Tanggung } \\
\text { Jawab }\end{array}$ & $\begin{array}{l}\text { Penyediaan data dosen dari PDPT untuk } \\
\text { akreditasi PT }\end{array}$ \\
\hline $\begin{array}{l}\text { Tujuan pada } \\
\text { EA }\end{array}$ & $\begin{array}{l}\text { Tercapainya ketersediaan data dosen } \\
\text { untuk PDPT sesuai jadwal yang } \\
\text { ditetapkan }\end{array}$ \\
\hline
\end{tabular}

Tabel 11. Role Catalogue Ka.Program Studi

\begin{tabular}{|l|l|}
\hline Aktor & Ka. Program Studi \\
\hline Role & $\begin{array}{l}\text { Penyelenggaran perkuliahan dan } \\
\text { pengawasan kinerja dosen }\end{array}$ \\
\hline $\begin{array}{l}\text { Tanggung } \\
\text { Jawab }\end{array}$ & $\begin{array}{l}\text { Penyediaan data mahasiswa dan LED } \\
\text { untuk akreditasi PT }\end{array}$ \\
\hline $\begin{array}{l}\text { Tujuan pada } \\
\text { EA }\end{array}$ & $\begin{array}{l}\text { Tercapainya ketersediaan data dosen } \\
\text { untuk PDPT sesuai jadwal yang } \\
\text { mahasiswa yang dapat digunakan setiap } \\
\text { saat }\end{array}$ \\
\hline
\end{tabular}

Tabel 12. Role Catalogue WK Bidang

Kemahasiswaan

\begin{tabular}{|l|l|}
\hline Aktor & WK. Bidang Kemahasiswaan \\
\hline Role & $\begin{array}{l}\text { Penyelenggaraan kegiatan tracer study dan } \\
\text { peningkatan mutu lulusan }\end{array}$ \\
\hline $\begin{array}{l}\text { Tanggung } \\
\text { Jawab }\end{array}$ & $\begin{array}{l}\text { Penyediaan data tracer study dan } \\
\text { informasi kesuksesan lulusan di dunia } \\
\text { kerja }\end{array}$ \\
\hline $\begin{array}{l}\text { Tujuan pada } \\
\text { EA }\end{array}$ & $\begin{array}{l}\text { Tercapainya ketersediaan data lulusan } \\
\text { sesuai jadwal yang dapat digunakan setiap } \\
\text { saat }\end{array}$ \\
\hline
\end{tabular}

Informasi yang tersimpan pada role di katalog, menunjukkan peran atau tugas yang dijalankan setiap stakeholder di unit nya masing-masing. Informasi tanggung jawab yang digunakan di katalog adalah tanggung jawab stakeholder dalam proses bisnis yang dibahas di penyusunan EA, yaitu dalam proses akreditasi PT. Tujuan pada EA di dalam katalog berisikan harapan yang ingin dicapai oleh setiap stakeholder.

\subsection{Phase C Information System Architecture}

Fase Information System Architecture bertujuan untuk mendeskripsikan data dan sistem informasi yang akan dibangun sesuai dengan katalog prinsip, solutionconcept diagram dan organization decomposition

diagram. Deskripsi prinsip data yang telah disusun di artefak katalog prinsip, menunjukkan permasalahan tentang status hubungan antara pemilik dan pengguna data, sehingga menyebabkan duplikasi data. Artefak dari fase $\mathrm{C}$ yang digunakan untuk menyelesaikan permasalahan tersebut adalah data entity/business function matrix, data to role access matrix, dan data to process access matrix. Artefak data entity/business function matrix ditunjukkan pada Tabel 13.

Tabel 13. Data Entity/Business Function Matrix

\begin{tabular}{|c|c|c|}
\hline Unit & Data Entity & Business Function \\
\hline LPSI & Rasio dosen & \multirow[t]{2}{*}{ Update data dosen } \\
\hline & $\begin{array}{l}\text { Jabatan } \\
\text { Fungsional }\end{array}$ & \\
\hline \multirow[t]{4}{*}{ LPPM } & Paper dosen & \multirow[t]{2}{*}{ Monitoring penelitian } \\
\hline & Sitasi & \\
\hline & Paper PKM & \multirow[t]{2}{*}{ Monitoring PKM } \\
\hline & LPJ PKM & \\
\hline \multirow[t]{3}{*}{ Program Studi } & Data PMB & $\begin{array}{l}\text { Penerimaan } \\
\text { Mahasiswa baru }\end{array}$ \\
\hline & Data mahasiswa & $\begin{array}{l}\text { Manajemen } \\
\text { perkuliahan }\end{array}$ \\
\hline & Data alumni & Tracer Study \\
\hline LPMI & $\begin{array}{l}\text { Data Audit Mutu } \\
\text { Internal }\end{array}$ & $\begin{array}{l}\text { Monitoring } \\
\text { penjaminan mutu }\end{array}$ \\
\hline $\begin{array}{l}\text { Bidang } \\
\text { Kemahasiswaan }\end{array}$ & Data alumni & Tracer Study \\
\hline $\begin{array}{l}\text { Senat \& } \\
\text { Pimpinan PT } \\
\text { (ketua) }\end{array}$ & LED & Evaluasi LED \\
\hline
\end{tabular}

Data entity pada artefak di Tabel 12 digunakan untuk menyusun artefak data to role matrix yang mendeskripsikan kronologi data mulai saat data dibuat sampai digunakan. Tabel 14 menunjukkan contoh data to role matrix dari beberapa data entity. Pemilihan artefak Data to role matrix ini dikarenakan permasalahan tentang data yang ditemui dari sistem berjalan adalah masih terjadinya redundansi data di beberapa bagian PT. Data to role matrix akan digunakan sebagai acuan anggota organisasi dalam pelaksanaan proses bisnis di masingmasing unit agar prinsip data di katalog prinsip hasil preliminary phase dapat dipenuhi. Artefak ini juga digunakan oleh bagian LPSI sebagai acuan pengembangan perangkat lunak yang dibutuhkan. 
Tabel 14. Data to role matrix

\begin{tabular}{|l|c|c|c|c|c|c|}
\hline Entitas \& Atribut Data & LPSI & LPPM & $\begin{array}{c}\text { Program } \\
\text { Studi }\end{array}$ & LPMI & $\begin{array}{c}\text { Bidang } \\
\text { Kemahasiswaan }\end{array}$ & $\begin{array}{c}\text { Senat \& } \\
\text { Pimpinan PT }\end{array}$ \\
\hline Data dosen & & & & & & \\
\hline NIDN & CRUD & R & R & R & & R \\
\hline Nama & CRUD & R & R & R & & R \\
\hline Mata kuliah & R & & CRUD & R & & \\
\hline Penelitian Dosen & & & & & & \\
\hline Judul paper & R & CRUD & RU & R & & R \\
\hline Tahun publikasi & R & CRUD & R & R & & R \\
\hline Nama jurnal & R & CRUD & R & & & R \\
\hline Volume jurnal & R & CRUD & R & & & R \\
\hline Nomor jurnal & R & CRUD & & & & R \\
\hline
\end{tabular}

\begin{tabular}{|c|c|c|c|c|c|c|}
\hline \multicolumn{7}{|c|}{ Pengabdian Kepada Masyarakat } \\
\hline Tempat pengabdian & $\mathrm{R}$ & CRUD & RU & $\mathrm{R}$ & & $\mathrm{R}$ \\
\hline Tanggal mulai & $\mathrm{R}$ & CRUD & $\mathrm{R}$ & $\mathrm{R}$ & & \\
\hline Tanggal selesai & $\mathrm{R}$ & CRUD & $\mathrm{R}$ & $\mathrm{R}$ & & \\
\hline Judul program pengabdian & $\mathrm{R}$ & CRUD & $\mathrm{R}$ & $\mathrm{R}$ & & $\mathrm{R}$ \\
\hline Judul paper pengabdian & & CRUD & $\bar{R}$ & $\mathrm{R}$ & & $\mathrm{R}$ \\
\hline \multicolumn{7}{|l|}{ Penerimaan Mahasiswa Baru } \\
\hline Jumlah pendaftar & $\mathrm{R}$ & & CRUD & $\mathrm{R}$ & $\mathrm{R}$ & $\mathrm{R}$ \\
\hline Jumlah mahasiswa baru & $\mathrm{R}$ & & CRUD & $\mathrm{R}$ & $\mathrm{R}$ & $\mathrm{R}$ \\
\hline Tahun PMB & $\mathrm{R}$ & & CRUD & $\mathrm{R}$ & $\mathrm{R}$ & $\mathrm{R}$ \\
\hline \multicolumn{7}{|l|}{ Tracer Study } \\
\hline Nomor anggota alumni & $\mathrm{R}$ & & $\mathrm{R}$ & $\mathrm{R}$ & CRUD & \\
\hline Nama alumni & $\mathrm{R}$ & & $\mathrm{R}$ & $\mathrm{R}$ & CRUD & \\
\hline Tempat kerja alumni & & & & $\mathrm{R}$ & CRUD & \\
\hline Tahun kelulusan & $\mathrm{R}$ & & $\mathrm{R}$ & $\mathrm{R}$ & CRUD & $\mathrm{R}$ \\
\hline
\end{tabular}

Unit yang memiliki status C (create) adalah unit yang bertanggungjawab untuk menghasilkan data. Unit yang berstatus Create hanya boleh ada satu agar tidak terjadi redundansi data. Status R (read) diperuntukkan bagi unit yang hanya mampu menggunakan data tanpa mengubah bentuk dan nilai data. Unit dengan status $U$ (update) berarti memiliki hak akses untuk memperbarui data. Perubahan data ini harus tercatat dalam sebuah log yang dapat diakses oleh unit dengan status C. Unit dengan status D (delete) menunjukkan unit yang berhak untuk menghapus data.

\section{KESIMPULAN}

Penyusunan EA dalam penelitian ini dilakukan berdasarkan karakteristik artefak yang disesuaikan dengan kebutuhan proses akreditasi PT. Pemahaman tentang visi misi PT dan tujuan utama setiap proses bisnis yang berjalan (baseline) dan yang akan dibenahi menjadi syarat awal yang harus dipenuhi untuk mendeskripsikan permasalahan yang muncul dari kondisi pada sistem berjalan agar dapat diuraikan dalam katalog prinsip. Pemilihan bentuk artefak TOGAF-ADM disesuaikan dengan standar dokumen yang digunakan di organisasi pengguna EA dan tidak dibatasi untuk sesuai dengan artefak standar TOGAF-ADM, selama dapat dipahami dengan mudah oleh aktor dan stakeholder EA.

Pada penelitian ini, artefak yang digunakan terdiri dari 8 jenis artefak. Artefak tersebut adalah katalog prinsip, Functional decomposition diagram baseline dan target, organizational decomposition diagram, role catalogue. Data entity/business function matrix, data to role access matrix.

\section{SARAN}

Penelitian lanjutan tentang TOGAF-ADM dapat dilakukan dengan mengeksplorasi metode penyusunan EA secara bottom-up dan integrasi beberapa EA. Penyusunan EA pada umumnya dilakukan top-bottom secara menyeluruh untuk satu organisasi namun akan menjadi beban bagi organisasi yang memiliki keterbatasan sumber daya. Metode bottom-up dan integrasi EA dapat di eksplorasi lebih lanjut tentang teknis penyusunan, metode integrasi EA dari beberapa bagian dan penyesuaian dengan visi misi organisasi.

\section{DAFTAR PUSTAKA}

Ansyori, R., Qodarsih, N., \& Soewito, B. (2018). A systematic literature review: Critical Success Factors to Implement Enterprise Architecture. Procedia Computer Science, 135, 43-51. https://doi.org/10.1016/j.procs.2018.08.148

Arif Abdul Hakim, M., Nofita Saputri, D., \& Rizanah Warang, R. (2019). Information Technology Architecture Design to Automate Enterprise Business Process Using TOGAF ADM. International Journal of Mechanical Engineering and Technology (IJMET), 10(03), 1525-1234.

Desfray, P., \& Raymond, G. (2014). Modeling Enterprise 
Architecture with TOGAF: A Practical Guide Using UML and BPMN. In Modeling Enterprise Architecture with TOGAF: A Practical Guide Using UML and BPMN. https://doi.org/10.1016/C2013-0-12657-8

Eichmann, O. C., Melzer, S., \& God, R. (2019). Modelbased development of a system of systems using unified architecture framework (UAF): A case study. SysCon 2019 - 13th Annual IEEE International Systems Conference, Proceedings, 18. https://doi.org/10.1109/SYSCON.2019.8836749

Foorthuis, R., van Steenbergen, M., Brinkkemper, S., \& Bruls, W. A. G. (2016). A theory building study of enterprise architecture practices and benefits. Information Systems Frontiers, 18(3), 541-564. https://doi.org/10.1007/s10796-014-9542-1

Gefan, M. (2018). The Analysis and Evaluation of Information System and Information Technology in the Parliament of Central Maluku Regency Using TOGAF ADM Method. International Journal of Computer Science and Software Engineering (IJCSSE), 7(7), 158-170.

Harrison, R. (2010). Study Guide TOGAF 9 Certified. The Open Group.

Kurniawan, B. (2011). Enterprise architecture planning sistem informasi pada perguruan tinggi swasta dengan zachman framework. Majalah Ilmiah UNIKOM, 9(1), 21-32.

Murti, D. N., Prasetyo, Y. A., \& Fajrillah, A. A. N. (2017). Perancangan Enterprise Architecture Pada Fungsi Sumber Daya Manusia (SDM) Di Universitas Telkom Menggunakan TOGAFADM. Jurnal Rekayasa Sistem \& Industri (JRSI), 4(01), 47. https://doi.org/10.25124/jrsi.v4i01.233

Nambela, Y., Zahra, D. F., \& Takwim, A. (2020). A Study Of Stakeholder Perspectives Of Enterprise Architecture Methodology (TOGAF Framework). Jurnal Riset Informatika, 2(4), 0-5.

Niemi, E., \& Pekkola, S. (2020). The Benefits of Enterprise Architecture in Organizational Transformation. Business and Information Systems Engineering, 62(6), 585-597. https://doi.org/10.1007/s12599-019-00605-3

Proenca, D., \& Borbinha, J. (2017). Enterprise architecture: A maturity model based on TOGAF ADM. Proceedings - 2017 IEEE 19th Conference on Business Informatics, CBI 2017, 1, 257-266. https://doi.org/10.1109/CBI.2017.38

Rouhani, B. D., Mahrin, M. N. Z. R., Nikpay, F., Ahmad, R. B., \& Nikfard, P. (2015). A systematic literature review on Enterprise Architecture Implementation Methodologies. Information and
Software Technology, 62(1), 1-20. https://doi.org/10.1016/j.infsof.2015.01.012

Saleem, F., \& Fakieh, B. (2020). Enterprise architecture and organizational benefits: A Case Study. Sustainability, 12(19), 23. https://doi.org/10.3390/su12198237

Setiawan, R. (2015). Perancangan Arsitektur Enterprise Untuk Perguruan Tinggi Swasta Menggunakan TOGAF ADM. Jurnal Algoritma, 12(1).

Soraya, V., \& Sari, W. S. (2019). Perancangan Enterprise Architecture Sistem Informasi dengan Menggunakan Framework TOGAF ADM pada CV. Garam Cemerlang. JOINS (Journal of Information System), 4(2), 148-156. https://doi.org/10.33633/joins.v4i2.3054

Suryana, T. (2017). Perancangan Arsitektur Teknologi Informasi Dengan Pendekatan Enterprise Architecture Planning. Jurnal Ilmiah Unikom, 10(2), 223-236.

Tao, Z. G., Luo, Y. F., Chen, C. X., Wang, M. Z., \& Ni, F. (2017). Enterprise application architecture development based on DoDAF and TOGAF. Enterprise Information Systems, 11(5), 627-651. https://doi.org/10.1080/17517575.2015.1068374

Thea Nisaa'Andi, S., Asti Amalia, N. F., \& Lubis, M. (2019). IT Roadmap to Improve Business Strategy using TOGAF ADM: A Case Study of Government-Owned Electricity Company. Journal of Physics: Conference Series, 1361(1). https://doi.org/10.1088/1742-6596/1361/1/012017

Undang-Undang No.12 Tahun 2012 Tentang Pendidikan Tinggi. (2012).

Wijaya, catur wahyu. (2017). Perancangan Enterprise Architecture Pada PT. Xyz Dengan Menggunakan Metode Togaf Adm. Institut Teknologi Sepuluh Nopember Surabaya.

Yudatama, U., Nazief, B. A. A., \& Hidayanto, A. N. (2018). Benefits and barriers as a critical success factor in the implementation of IT governance: Literature review. 2017 International Conference on ICT for Smart Society, ICISS 2017, 2018-Janua, 1-6. https://doi.org/10.1109/ICTSS.2017.8288869

\section{UCAPAN TERIMA KASIH}

Terima kasih kami sampaikan kepada Kementerian Pendidikan Nasional yang telah membantu pembiayaan penelitian ini melalui skema program Penelitian Dosen Pemula dengan Surat Keputusan Nomor

1867/E4/AK.04/2021 dan Perjanjian / Kontrak Nomor 30/LL11/KM/2021, sehingga penelitian ini dapat terlaksana. 